\title{
Maternal Health Service Uptake Is Associated with a Higher Skin- to-Skin Care Practice in Ethiopia: Result from a National Survey
}

\author{
Dabere Nigatu $\left(\mathbb{D},{ }^{1}\right.$ Gedefaw Abeje $\mathbb{D}^{1},{ }^{1}$ Alemayehu G. Mekonnen $\mathbb{D}^{2},{ }^{2}$ Muluken Azage $\mathbb{D}^{3}{ }^{3}$ \\ and Daniel Bogale $\mathbb{D i}^{4}$ \\ ${ }^{1}$ Department of Reproductive Health and Population Studies, School of Public Health, College of Medicine and Health Sciences, \\ Bahir Dar University, Bahir Dar, Ethiopia \\ ${ }^{2}$ Department of Nursing, College of Health Science, Debre Berhan University, Debre Berhan, Ethiopia \\ ${ }^{3}$ Department of Environmental Health, School of Public Health, College of Medicine and Health Sciences, Bahir Dar University, \\ Bahir Dar, Ethiopia \\ ${ }^{4}$ Department of Public Health, College of Health Sciences, Arsi University, Asella, Ethiopia
}

Correspondence should be addressed to Dabere Nigatu; daberen@yahoo.com

Received 1 September 2020; Revised 30 November 2020; Accepted 4 December 2020; Published 17 December 2020

Academic Editor: Renato T Souza

Copyright (C) 2020 Dabere Nigatu et al. This is an open access article distributed under the Creative Commons Attribution License, which permits unrestricted use, distribution, and reproduction in any medium, provided the original work is properly cited.

\begin{abstract}
Background. Though skin-to-skin care (SSC) is becoming an important newborn care package at both facility and community levels in Ethiopia, there is a lack of evidence to monitor the progress at each level. Therefore, this study is aimed at quantifying the proportion of SSC at both national and regional levels and identifying factors that affect SSC uptake in Ethiopia. Method. We used the 2016 Ethiopia Demographic and Health Survey data. The survey employed a multistage cluster sampling method. We included 7,488 live births in the analysis. The factors influencing SSC practice were identified using a multivariable logistic regression model. We reported adjusted odds ratios (AORs) with 95\% confidence intervals (CIs). Results. In Ethiopia, 24.3\% of mothers practiced SSC for their newborns $(95 \% \mathrm{CI}=23.3,25.2)$. The highest proportion was in Addis Ababa (63\%), and the lowest was in the Somali region (14.5\%). Attending 1-4 antenatal care $(\mathrm{AOR}=1.51,95 \% \mathrm{CI}=[1.08,2.12]$, giving birth at health facility $(\mathrm{AOR}=4.51,95 \% \mathrm{CI}=[2.16,9.44]$, and having female births $(\mathrm{AOR}=1.24,95 \% \mathrm{CI}=[1.01,1.54])$ were associated with more odds of practicing SSC. However, giving birth by the cesarean section had resulted in lower odds of practicing SSC $(\mathrm{AOR}=0.37,95 \% \mathrm{CI}=[0.22,0.63])$. Regions with reduced odds of SSC practice include Amhara $(\mathrm{AOR}=0.57,95 \% \mathrm{CI}=[0.40$, $0.82])$, Somali $(\mathrm{AOR}=0.51,95 \% \mathrm{CI}=[0.31,0.83])$, and Southern Nations, Nationalities, and People $(\mathrm{AOR}=0.64,95 \% \mathrm{CI}=[0.43$, 0.94]). Conclusions. The SSC practice was low in Ethiopia with a high level of variation between regions. In Ethiopia, maternal health service uptake affects the SSC of the newborns. Well-tailored community-level interventions are needed to increase skinto-skin care practice among home delivery mothers.
\end{abstract}

\section{Background}

Globally, the preterm birth rate was estimated to be $10.6 \%$, equating to 14.8 million live preterm births in 2014. From these, 12 million $(81.1 \%)$ of the preterm births occurred in Asia and sub-Saharan Africa [1]. In 2015, an estimated 20.5 million live births were low birth weight (LBW), 91\% from low- and middle -income countries [2,3]. The large burden of preterm births and low birth weight calls for more effective interventions for primary prevention including scale up of feasible and evidence-based interventions such as Kangaroo Mother Care (KMC) [4].

The KMC is care of preterm and/or low birth weight babies carried skin-to-skin with the mother including early breastfeeding and follow-up [5, 6]. Skin-to-skin care (SSC) is the prime component of KMC. The World Health Organization defined SSC as placing the naked baby on the mother's bare abdomen or chest immediately or in less than 10 minutes after birth or soon afterwards [7]. It is easy-topractice method but has a substantial benefit in promoting 
the health and well-being of infants born preterm as well as full-term [5]. In resource-limited countries like Ethiopia, skin-to-skin care is an effective and safe alternative/substitute to conventional neonatal care for preterm/LBW infants [5, 8]. Previous studies revealed that SSC for preterm and/or low birth weight newborns associated with reduced mortality and morbidity [8-11], improved maternal-infant attachment (emotional and caring behavior) [8, 11-13], improved infant growth (increase weight, head circumference, and length gain) $[8,11,14]$, and enhanced early initiation of breastfeeding [15]. However, SSC remains unavailable at scale in most low-income countries [10], and there is also a lack of studies about SSC in low-income countries [16].

In Ethiopia, SSC was introduced in 1996 at the Tikur Anbesa Hospital. Since then, the SSC services have been expanded to other hospitals and health facilities at all levels [17]. In settings like Ethiopia where many childbirths are taking place at home (up to 52\%) [18], only facility-based implementation of SSC may not be adequate to bring the desired child health outcomes. In 2013, Ethiopia launched a communitybased newborn care including SSC as a means of bringing lifesaving care to mothers and newborns at the community level with Health Extension Workers and Women Development Armies as a vehicle of its implementation $[19,20]$. Since then, integrated and multilevel interventions (i.e., both at community- and facility-level) were instigated in the most populous regions of Ethiopia (Amhara, Oromia, SNNP, and Tigray) to promote early SSC [21]. The community level early SSC promotion is irrespective of the birth weight. This is because of two main reasons: (1) there is no established community/household level system to ensure all births have measured birth weight in the country, and (2) more than half of the births are taking place at home. Even there are births occurred at a health facility, but lack registered birth weight. Regarding the succees story, there are evidence of improving newborn care at the community level and increased maternal satisfaction and empowerment with the care of their newborns $[13,20,22]$. Therefore, SSC becomes the high impact newborn care package at both facility and community levels in Ethiopia [23]. Thus, both national and/or subnational research are becoming the cornerstone of the strategy to monitor progress at the desired level. However, except for few pocket studies done so far, there is inadequate data on the proportion of SSC at the national level. Therefore, the current study is aimed at determining the proportion of SSC at both national and regional levels. Moreover, the study identified factors that affect SSC uptake using a nationally representative household survey. The SSC at birth is one of the strategic interventions in place in the country to reduce neonatal and child morbidity and mortality. Thus, the current findings can be applied to improve the level of skin-to-skin care practice at the community and health facility levels. It can also be used as an essential input to track or evaluate the performance of programs that have been in place in the area of skin-to-skin care practice in the country.

\section{Methods}

2.1. Data Sources. The data source for this analysis was the 2016 Ethiopia Demographic and Health Survey (EDHS). It is a nationally representative household survey carried out every five years since 2000. The datasets of EDHS surveys are freely available, and we have accessed it from the online repository of the Demographic and Health Survey (DHS) Program website upon request via a link https://www .dhsprogram.com/data/available-datasets.cfm.

2.2. Sample Size and Sampling Procedure. The sample for the 2016 EDHS was designed to provide estimates of key indicators both at national and regional levels. List of enumeration areas (EAs) generated for the 2007 Ethiopia Population and Housing Census was used as a sampling frame for the 2016 EDHS. The DHS used a stratified two-stage cluster sampling technique. In the first stage, 645 EAs (202 urban and 443 rural areas) were selected with probability proportional to the EA size. Then, household listing was done for the selected EAs. In the second stage, a fixed number of 28 households per cluster were selected using the newly created household list as a sampling frame [24].

A total of 11,023 live births born from 15,683 women in the last 5 years preceding the survey. This study considered only the most recent births to a woman taking place in the five years preceding the survey. For two reasons, we preferred to rely only on the most recent births. The first reason is to reduce recall bias, and the second reason is that some important variables (for example, antenatal care) are assessed only for the most recent births. When we consider only the last birth to a woman, we reached a sample of 7,590 live births. From 7,590 live births, we excluded 102 mothers who did not remember SSC practice for their last birth. Therefore, the current analysis included 7,488 weighted sample (7,060 unweighted sample) of index live births (Figure 1).

2.3. Study Variable Measurement. Skin-to-skin care is an outcome variable. In the 2016 EDHS, mothers who gave live births in the last five years preceding the survey were asked about skin-to-skin care practices. The question was articulated this way: "immediately after the birth, was (NAME) put directly on the bare skin of your chest?" The response options were "yes", “no," or "I don't know." We excluded the "I do not know" responses from the analysis.

The explanatory variables include maternal age at delivery, maternal education, maternal current employment status, maternal current marital status, place of residence, region, wealth index, antenatal care visits, place of delivery, cesarean section (CS) delivery, number of living children, sex of the child, baby's size at birth (as reported by mothers), parity, and childbirth attendant. The details of explanatory variables coding are provided as supplementary material (see Table S1). The 2016 EDHS has a question to assess maternal perceptions of the baby's birth size. The mothers were asked to retrospectively classify their babies' sizes at birth as "very large," "larger than average," "average," "smaller than average," or "very small." Then, we recoded the birth size into two categories: very large, larger than average, and average responses taken into a category of "average or above average", whereas smaller than average and very small responses taken into a category of "small."

The DHS collected information about the number and kinds of consumer goods and the housing characteristics a 


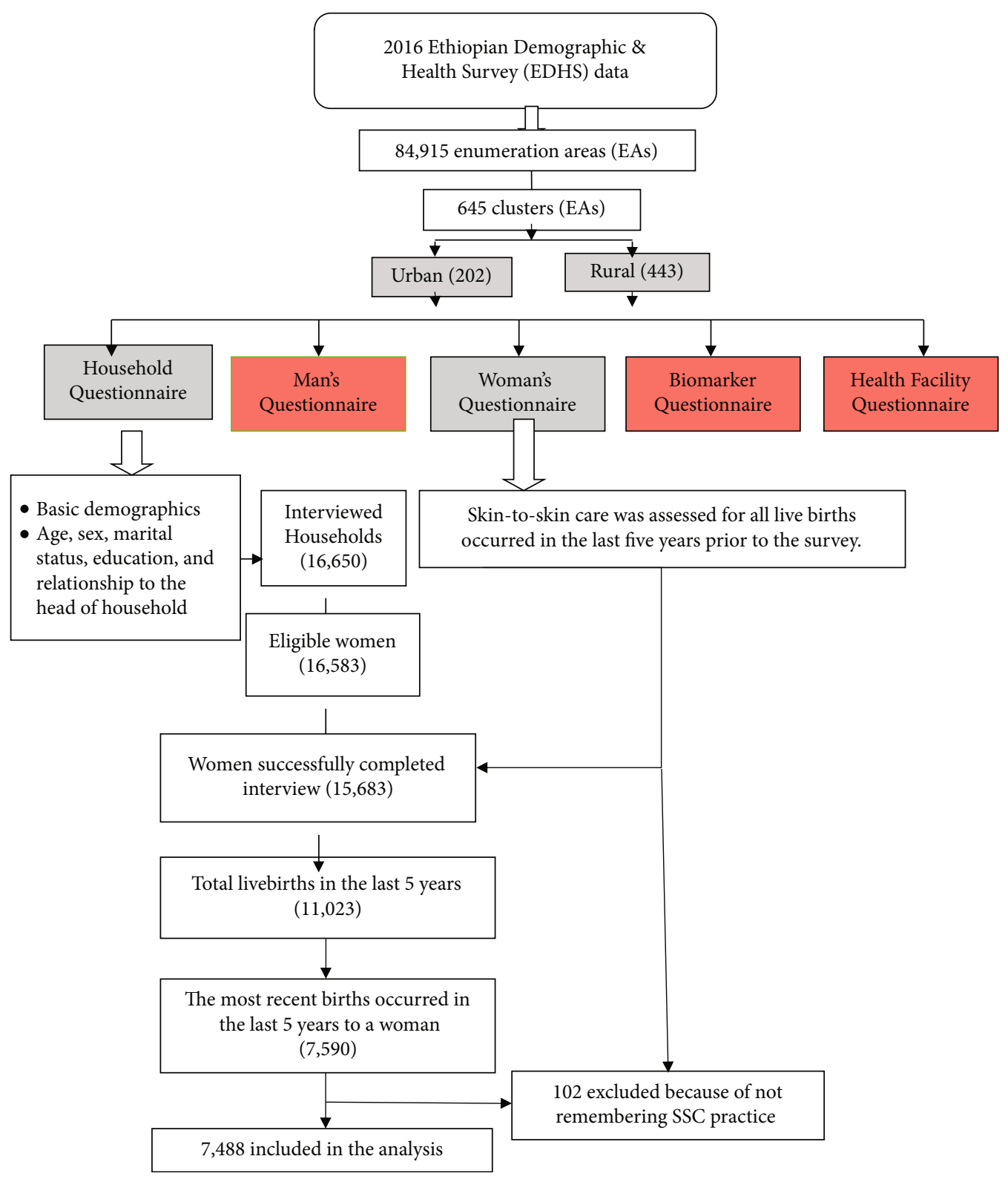

FIGURE 1: The sample selection procedure flowchart for skin-to-skin care practice, EDHS, 2016.

household owns. These data were used to generate wealth index scores using principal component analysis. Finally, the wealth index scores were categorized into quintiles $[24,25]$.

2.4. Data Analysis. The data was analyzed using the STATA version 14.0 statistical software package. Recoding of some variables was done to suit the analysis. We considered sample weighting and sampling design during analysis because the EDHS data derived from a complex survey. We have used the SVYSET Stata command to declare a complex survey design for our dataset and the SVY command whenever we run estimates.

Multivariable logistic regression model was fitted using binary logistic regression analysis. Variables having $p$ value less than 0.25 in the bivariable logistic regression analysis were candidate variables for the multivariable logistic regression model [26]. The enter method was applied to fit the logistic regression model. The association between explanatory variables and outcome variable (skin-to-skin care practice) was quantified using odds ratio with $95 \%$ confidence interval. The presence of significant association was declared at $p$ value less than 0.05 , or if the reported confidence intervals for odds ratio do not include one.

This manuscript is prepared following the Strengthening the Reporting of Observational Studies in Epidemiology (STROBE) checklist for cross-sectional study reporting guidelines [27] (Table S2).

2.5. Ethical Considerations. The National Research Ethics Review Committee at the Federal Democratic Republic of 
Ethiopia Ministry of Science and Technology and the Institutional Review Board of ICF International reviewed and approved the 2016 EDHS survey protocol. The authors got a permission from the ICF-DHS program to use the DHS data and accessed through "https://www.dhsprogram.com/ data/dataset_admin/login_main.cfm.” Interested readers can refer the 2016 EDHS country report for further information about the survey protocol [24].

\section{Results}

3.1. Sociodemographic Characteristics and Maternal Health Services Uptake. A total of 7,488 mothers who had live births were included in the present analysis. A sample of 7,488 was achieved after exclusion of 102 mothers who did not remember skin-to-skin care practice for their last birth. Eighty percent of the mothers were in the age range of 19-34 years. About two-thirds, 63.5\%, of mothers had no formal education. About $88 \%$ of the mothers were rural residents, and seven out of ten mothers were not employed. Majority, $94 \%$, of the mothers were married. About $19 \%$ of the mothers were at their first birth, and $27.2 \%$ of the babies were small size at birth. Thirty-seven percent of the mothers did not attend antenatal care for their index pregnancy, 69\% gave birth at home, $32.4 \%$ assisted by skilled birth attendant, and $1.8 \%$ gave birth by the cesarean section (Table 1). From 5171 home deliveries, $77.2 \%$ assisted by nonskilled birth attendants, and $20.2 \%$ delivered without any assistant (Figure 2). The distribution of the birth assistant by regions in Ethiopia and type of residence (urban/rural) was provided as supplementary data (Table S3).

In Ethiopia, 24.3\% of mothers practiced skin-to-skin care for their newborns $(95 \% \mathrm{CI}=23.3,25.2)$ (Figure 3$)$. The proportions of skin-to-skin care varies across regions of Ethiopia; the highest was in Addis Ababa (63\%), and the lowest was in the Somali region (14.5\%). The proportion of skinto-skin care practices was higher among urban mothers (53\%) compared to rural mothers $(20 \%)$. The proportion of SSC was as low as $10 \%$ among mothers who had no antenatal care visit during the index pregnancy and as high as $41 \%$ among mothers who had attended more than four ANC visits during the index pregnancy. About $59 \%$ of the mothers who gave birth at health facilities practiced SSC, while only $9 \%$ of the mothers who gave birth at home practiced SSC for their most recent birth. Higher proportion of mothers practiced SSC if they were primiparous (35.6\%) than multiparous $(21.6 \%)$. The proportion of SSC practice was higher for mothers who gave birth by CS $(35.6 \%)$ as compared to mothers who gave birth without CS (24\%). Higher proportion of mothers who were assisted by skilled birth attendant (57\%) practiced SSC as compared to mothers who were assisted by nonskilled attendant (8\%) (Table 1).

3.2. Factors Affecting Skin-to-Skin Care Practice. This study revealed the presence of significant differences in SSC practice by residential regions, ANC status, place of delivery, mode of delivery, and sex of the child. As compared to mothers who lived in the Tigray region, those mothers who lived in the Amhara region $(\mathrm{AOR}=0.57,95 \% \mathrm{CI}=[0.40$,
$0.82])$, Somali region $(\mathrm{AOR}=0.51,95 \% \mathrm{CI}=[0.31,0.83])$, and $\mathrm{SNNP}$ region $(\mathrm{AOR}=0.64,95 \% \mathrm{CI}=[0.43,0.94])$ had lower odds of SSC practice (Table 2).

We found that attending ANC, giving birth at health facility, and mode of delivery had an effect on SSC practice. Mothers who had attended 1-4 ANC (AOR $=1.51,95 \% \mathrm{CI}$ $=[1.08,2.12]$ visits had higher odds of SSC practice compared to those mothers who had no ANC visit. Similarly, those mothers who gave birth at health facilities were about 2 times higher odds of SSC practice $(\mathrm{AOR}=4.51,95 \% \mathrm{CI}=$ $2.16,9.44]$ ) than those mothers who gave birth at home. However, those mothers who gave birth by CS had 63\% less odds of practicing SSC $(\mathrm{AOR}=0.37,95 \% \mathrm{CI}=[0.22,0.63])$. The odds of practicing SSC were higher if a child was female than male $(\mathrm{AOR}=1.24,95 \% \mathrm{CI}=[1.01,1.54])$ (Table 2$)$.

\section{Discussion}

The current study showed the presence of large variations in skin-to-skin care practice between regions of Ethiopia. It also revealed the role of ANC follow-up, place of delivery, mode of delivery, and sex of children for skin-to-skin care of newborns immediately after birth in Ethiopia.

The national level proportion of SSC practice was $24.3 \%$ (95\% CI: 23.3, 25.2) with substantial variation between regions of Ethiopia. Addis Ababa (63\%) was the region with the highest proportion of skin-to-skin care, while the Somali region (14.5\%) was with the lowest proportion of skin-to-skin care. The high variation among regions might be because of the gap in the initiation and scale up of the community-based newborn care practices across the regions. Usually, most maternal, newborn, and child health programs including community-based newborn care packages are piloted/introduced in the four most populous regions of Ethiopia-Amhara, Oromia, Tigray, and the Southern Nations, Nationalities, and People's (SNNP) regions. For example, the last ten kilometers (L10K) project $[28,29]$, the IDEAS (Informed Decisions for Actions in Maternal and Newborn Health) project [19], and MCHIP (Maternal and Child Health Integrated Program) [21] were initiated and implemented in these four regions. The national proportion is greater than the proportion in India (14.5\%) [30] and in Nepal (16.5\%) [31] where as it is lower than the proportion reported in Sri Lanka (50.4\%). The Sri Lanka finding is higher than our finding because the Sri Lanka study is a preintervention survey among deliveries in the health facility. A multisite study reported SSC practice in Eastern India (15\%) and in Bangladesh (30\%) [32].

In this study, attending ANC had positively influenced SSC of newborns during the immediate postpartum period. This might be due to the influential role of antenatal counseling on immediate newborn care practices including skin-toskin care of newborns. Existing evidence also supports the positive association between receiving antenatal counseling and SSC practice during the immediate postpartum period [21]. Besides, a qualitative study remarked that antenatal awareness could be a feasible remedy to overcoming knowledge and attitude related-barriers of KMC practice in the community [33].

The current study also suggested that giving birth at a health facility significantly increased skin-to-skin care 
TABLE 1: Proportion of SSC by sociodemographic characteristics and maternal health services in Ethiopia, EDHS 2016.

\begin{tabular}{|c|c|c|c|}
\hline Variables & Frequency & Percent & Proportion of SSC practice with $95 \%$ CI \\
\hline \multicolumn{4}{|l|}{ Maternal age at delivery } \\
\hline$<=18$ & 558 & 7.5 & $24.3[19.25,30.20]$ \\
\hline $19-34$ & 5,612 & 74.9 & $25.8[23.39,28.31]$ \\
\hline$>=35$ & 1,318 & 17.6 & $17.7[14.38,21.68]$ \\
\hline \multicolumn{4}{|l|}{ Educational status } \\
\hline No formal education & 4,753 & 63.5 & $18.1[15.75,20.71]$ \\
\hline Primary & 2,118 & 28.3 & $29.8[26.68,33.12]$ \\
\hline Secondary & 412 & 5.5 & $54.0[46.05,61.68]$ \\
\hline Higher & 205 & 2.7 & $49.9[37.95,61.87]$ \\
\hline \multicolumn{4}{|l|}{ Place of residence } \\
\hline Urban & 921 & 12.3 & $53.2[46.81,59.47]$ \\
\hline Rural & 6,567 & 87.7 & $20.2[17.88,22.72]$ \\
\hline \multicolumn{4}{|l|}{ Regional distribution } \\
\hline Tigray & 529 & 7.1 & $47.8[40.15,55.47]$ \\
\hline Afar & 69 & 0.9 & $15.8[12.20,20.25]$ \\
\hline Amhara & 1,610 & 21.5 & $20.8[17.58,24.36]$ \\
\hline Oromia & 3,099 & 41.4 & $20.6[16.72,25.10]$ \\
\hline Somali & 266 & 3.6 & $14.5[10.82,19.25]$ \\
\hline Benishangul-Gumuz & 80 & 1.1 & $30.3[22.62,39.16]$ \\
\hline SNNPR & 1,585 & 21.2 & $25.6[19.36,28.43]$ \\
\hline Gambela & 20 & 0.3 & $34.2[28.18,40.67]$ \\
\hline Harari & 17 & 0.2 & $43.1[35.74,50.69]$ \\
\hline Addis Ababa & 180 & 2.4 & $62.7[55.80,69.12]$ \\
\hline Dire Dawa & 33 & 0.4 & $47.9[40.92,54.98]$ \\
\hline \multicolumn{4}{|l|}{ Wealth index } \\
\hline Poorest & 1,642 & 21.9 & $13.0[10.12,16.60]$ \\
\hline Poorer & 1,642 & 21.9 & $19.0[15.69,22.87]$ \\
\hline Middle & 1,574 & 21.0 & $22.2[18.39,26.50]$ \\
\hline Richer & 1,411 & 18.9 & $26.2[22.46,30.32]$ \\
\hline Richest & 1,219 & 16.3 & $46.8[42.40,51.31]$ \\
\hline \multicolumn{4}{|l|}{ Current employment status } \\
\hline Not employed & 5,353 & 71.5 & $22.2[19.87,24.81]$ \\
\hline Employed & 2,135 & 28.5 & $29.3[25.96,32.86]$ \\
\hline \multicolumn{4}{|l|}{ Current marital status } \\
\hline Never in union & 56 & 0.75 & $39.3[22.26,59.35]$ \\
\hline Currently in union & 7,011 & 93.6 & $24.2[21.91,26.56]$ \\
\hline Formerly in union & 421 & 5.6 & $23.8[18.88,29.61]$ \\
\hline \multicolumn{4}{|l|}{ Sex of child } \\
\hline Male & 3,894 & 52.0 & $22.9[20.43,25.53]$ \\
\hline Female & 3,594 & 48.0 & $25.7[22.88,28.83]$ \\
\hline \multicolumn{4}{|c|}{ Perceived baby size at birth $(n=7,423)$} \\
\hline Small & 2,022 & 27.2 & $21.2[18.12,24.56]$ \\
\hline Normal (average or above) & 5,401 & 72.8 & $25.6[23.21,28.06]$ \\
\hline \multicolumn{4}{|l|}{ Antenatal care visits $(n=7,473)$} \\
\hline No visit & 2,804 & 37.5 & $10.2[8.09,12.86]$ \\
\hline $1-4$ visit & 3,498 & 46.8 & $29.7[26.74,32.89]$ \\
\hline$>4$ visits & 1,171 & 15.7 & $41.4[37.15,45.69]$ \\
\hline
\end{tabular}


TABLE 1: Continued.

\begin{tabular}{|c|c|c|c|}
\hline Variables & Frequency & Percent & Proportion of SSC practice with 95\% CI \\
\hline \multicolumn{4}{|l|}{ Place of delivery } \\
\hline Home & 5,171 & 69.1 & $8.8[6.99,11.10]$ \\
\hline Health facility & 2,317 & 30.9 & $58.7[54.98,62.24]$ \\
\hline \multicolumn{4}{|l|}{ Cesarean section delivery } \\
\hline No & 7,353 & 98.2 & $24.0[21.81,26.42]$ \\
\hline Yes & 135 & 1.8 & $35.6[25.77,46.82]$ \\
\hline \multicolumn{4}{|l|}{ Parity } \\
\hline First birth & 1,407 & 18.8 & $35.6[31.01,40.50]$ \\
\hline Second birth or beyond & 6,081 & 81.2 & $21.6[19.33,24.10]$ \\
\hline \multicolumn{4}{|l|}{ Childbirth attendant } \\
\hline Skilled attendant & 2,431 & 32.4 & $56.9[53.30,60.45]$ \\
\hline Nonskilled attendant & 4,011 & 53.6 & $8.0[6.15,10.22]$ \\
\hline No attendant & 1,046 & 14.0 & $11.0[7.51,15.77]$ \\
\hline
\end{tabular}

CI: confidence interval; EDHS: Ethiopian Demographic and Health survey; SNNP: Southern Nations, Nationalities, and People; SSC: skin-to-skin care.

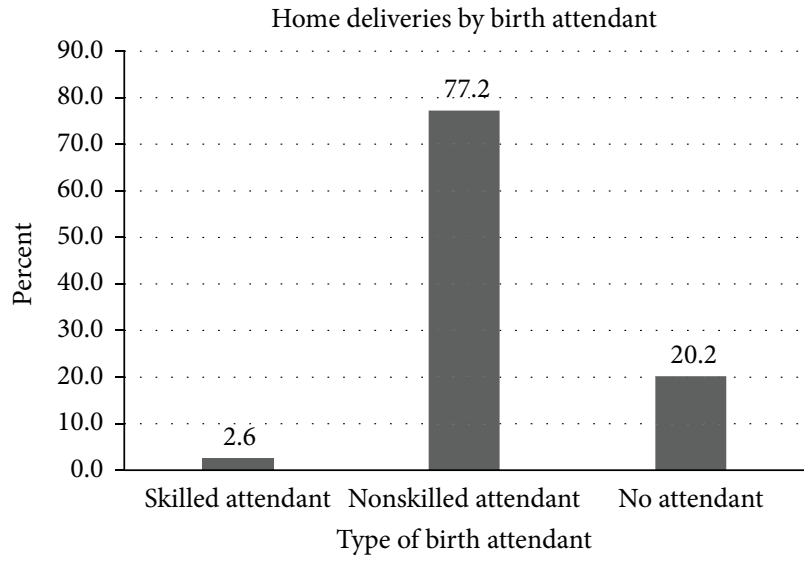

FIgURe 2: The distribution of home deliveries by type of birth attendants, EDHS 2016. Skilled attendant includes doctors/physicians, nurses, midwives, public health officers, and health extension workers; nonskilled attendant includes traditional birth attendants, relatives/friends/neighbors, and other persons.

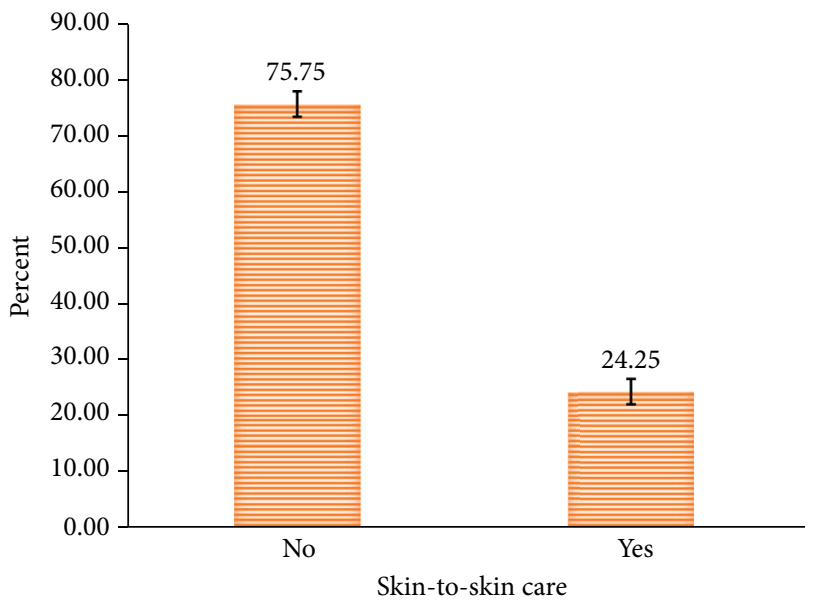

FIGURE 3: The proportion of mothers who had practiced skin-toskin care in Ethiopia, EDHS, 2016. practice of newborns. In fact, giving birth at a health facility can give a better opportunity for health professionals to assess newborn conditions and suggest mothers for skin-toskin care of their newborns. Another study done in Ethiopia also reported that SSC was significantly higher among facility births than home births [21].

We observed a higher proportion of SSC practice among mothers who gave birth by CS than without CS. When the role of confounders controlled via the multivariable regression analysis, we found reversed association. Giving birth via the cesarean section had a negative influence on practice of skin-to-skin care. This might be because of the fact that those women who undergo CS may take longer time to recover from anesthesia, and the CS site may be painful and need time to heal. These problems combined make positioning the newborn in skin-to-skin contact with the mother difficult during the immediate postpartum period. A systematic review of evidences from low- and middle-income countries also reported pain/fatigue as top-ranked barriers of $\mathrm{KMC}$ practice [34].

The sex of the newborn also affects skin-to-skin care practice of the mothers. In our findings, mothers have a greater tendency to practice skin-to-skin care for female newborns. This finding may be difficult to explain, but it may be associated because of the birth size/weight difference between the two sexes. The birth size/weight differences between the two sexes evidenced in several studies reported that male newborns tended to be larger and heavier than females at birth [35-37].

The current study had evaluated the relationship between the baby's birth size and SSC practice. The maternally perceived baby size at birth did not show significant association with skin-to-skin care practice of newborns during the immediate postpartum period. The lack of association might be because of inaccurate classification of the baby size at birth. The problem of misclassification was addressed in a previous study reporting that maternal assessment of the baby size is an inaccurate proxy indicator of low birth weight in Ethiopia [38]. This implies the importance of noncriteria- 
TABLE 2: Factors affecting skin-to-skin care practice in Ethiopia, EDHS, 2016.

\begin{tabular}{|c|c|c|}
\hline \multirow{2}{*}{ Explanatory variables } & \multicolumn{2}{|c|}{ Practiced skin-to-skin care } \\
\hline & COR $[95 \% \mathrm{CI}]$ & AOR $[95 \% \mathrm{CI}]$ \\
\hline \multicolumn{3}{|l|}{ Mother's age } \\
\hline$<=18$ & 1.00 & 1.00 \\
\hline $19-35$ & $1.08[0.80,1.46]$ & $1.28[0.87,1.87]$ \\
\hline$>=35$ & $0.67[0.46,0.99]$ & $0.81[0.47,1.38]$ \\
\hline \multicolumn{3}{|l|}{ Mother's education } \\
\hline No formal education & 1.00 & 1.00 \\
\hline Primary & $1.92[1.60,2.31]$ & $1.03[0.82,1.29]$ \\
\hline Secondary & $5.31[3.72,7.57]$ & $1.10[0.68,1.78]$ \\
\hline Higher & $4.51[2.68,7.60]$ & $0.73[0.36,1.50]$ \\
\hline \multicolumn{3}{|l|}{ Place of residence } \\
\hline Urban & $4.49[3.34,6.04]$ & $1.27[0.83,1.93]$ \\
\hline Rural & 1.00 & 1.00 \\
\hline \multicolumn{3}{|l|}{ Region } \\
\hline Tigray & 1.00 & 1.00 \\
\hline Afar & $0.21[0.13,0.32]$ & $0.68[0.43,1.07]$ \\
\hline Amhara & $0.29[0.20,0.42]$ & $0.57[0.40,0.82]^{*}$ \\
\hline Oromia & $0.28[0.19,0.42]$ & $0.69[0.44,1.07]$ \\
\hline Somali & $0.19[0.12,0.29]$ & $0.51[0.31,0.83]^{*}$ \\
\hline Benishangul-Gumuz & $0.47[0.28,0.78]$ & $0.95[0.62,1.48]$ \\
\hline SNNPR & $0.34[0.23,0.50]$ & $0.64[0.43,0.94]^{*}$ \\
\hline Gambela & $0.57[0.37,0.86]$ & $0.71[0.47,1.08]$ \\
\hline Harari & $0.83[0.53,1.28]$ & $1.00[0.66,1.49]$ \\
\hline Addis Ababa & $1.84[1.21,2.80]$ & $0.94[0.58,1.54]$ \\
\hline Dire Dawa & $1.01[0.66,1.53]$ & $1.05[0.70,1.57]$ \\
\hline \multicolumn{3}{|l|}{ Wealth index quintile } \\
\hline Poorest & 1.00 & 1.00 \\
\hline Poorer & $1.57[1.12,2.20]$ & $1.10[0.70,1.72]$ \\
\hline Middle & $1.90[1.35,2.69]$ & $1.28[0.86,1.92]$ \\
\hline Richer & $2.37[1.67,3.37]$ & $1.38[0.89,2.14]$ \\
\hline Richest & $5.88[4.20,8.23]$ & $1.20[0.72,1.99]$ \\
\hline \multicolumn{3}{|l|}{ Employment status } \\
\hline Not employed & 1.00 & 1.00 \\
\hline Employed & $1.45[1.20,1.74]$ & $1.02[0.82,1.27]$ \\
\hline \multicolumn{3}{|l|}{ Marital status } \\
\hline Never in union & 1.00 & 1.00 \\
\hline Currently in union & $0.49[0.22,1.11]$ & $0.84[0.30,2.40]$ \\
\hline Formerly in union & $0.48[0.20,1.14]$ & $0.80[0.27,2.39]$ \\
\hline \multicolumn{3}{|l|}{ Sex of child } \\
\hline Male & 1.00 & 1.00 \\
\hline Female & $1.17[0.99,1.39]$ & $1.24[1.01,1.54]^{*}$ \\
\hline \multicolumn{3}{|l|}{ Perceived baby size at birth } \\
\hline Small & $0.78[.65,0.94]$ & $0.90[0.71,1.15]$ \\
\hline Normal (average or above average) & 1.00 & 1.00 \\
\hline \multicolumn{3}{|l|}{ Antenatal care visits } \\
\hline No visits & 1.00 & 1.00 \\
\hline $1-4$ visits & $3.71[2.80,4.90]$ & $1.51[1.08,2.12]^{*}$ \\
\hline$>4$ visits & $6.18[4.61,8.30]$ & $1.43[1.00,2.05]$ \\
\hline
\end{tabular}


TABLE 2: Continued.

\begin{tabular}{|c|c|c|}
\hline \multirow{2}{*}{ Explanatory variables } & \multicolumn{2}{|c|}{ Practiced skin-to-skin care } \\
\hline & COR $[95 \% \mathrm{CI}]$ & $\mathrm{AOR}[95 \% \mathrm{CI}]$ \\
\hline \multicolumn{3}{|l|}{ Place of delivery } \\
\hline Home & 1.00 & 1.00 \\
\hline Health facility & $14.64[11.13,19.27]$ & $4.51[2.16,9.44]^{* *}$ \\
\hline \multicolumn{3}{|l|}{ Cesarean section delivery } \\
\hline No & 1.00 & 1.0 \\
\hline Yes & $1.75[1.07,2.84]$ & $0.37[0.23,0.63]^{* *}$ \\
\hline Number of living children & $0.87[0.82,0.92]$ & $1.05[0.96,1.16]$ \\
\hline \multicolumn{3}{|l|}{ Parity } \\
\hline First birth & $2.01[1.59,2.53]$ & $1.14[0.81,1.60]$ \\
\hline Second birth or beyond & 1.00 & 1.00 \\
\hline \multicolumn{3}{|l|}{ Childbirth attendant } \\
\hline Skilled attendant & $10.69[6.83,16.73]$ & $2.11[0.90,4.94]$ \\
\hline Nonskilled attendant & $0.70[0.47,1.05]$ & $0.69[0.46,1.05]$ \\
\hline No attendant & 1.00 & 1.00 \\
\hline
\end{tabular}

${ }^{*}$ Variables with $p<0.05$ in the multivariable regression model, ${ }^{* *}$ variables with $p<0.01$ in the multivariable regression model; AOR: adjusted odds ratio; CI: confidence interval; COR: crude odds ratio; SNNP: Southern Nations, Nationalities, and People; SSC: skin-to-skin care.

based (i.e., irrespective of birth size) application of SSC at the community level.

Being a nationally representative data with large sample and making use of the most recent births taking place in the last five years prior to the survey can be the strength of this study. However, the results of this study may not be free of recall bias because skin-to-skin care practice was assessed for the index live births taking place in the last five years preceding the survey. Birth weight, a potential predictor variable for SSC practice, was not considered because of a large missing (85\%) in the 2016 EDHS data [24, 38]. We have considered the baby's birth size which is a proxy indicator of birth weight where there is a lack of data on birth weight [39].

\section{Conclusions}

The proportion of skin-to-skin care practices was low in Ethiopia with significant variation across regions. The study also revealed the significant role of ANC follow-up, place of delivery, mode of delivery, and sex of child for SSC of newborns immediately after birth in Ethiopia. We recommend a community-based promotion of SSC at full scale to increase skin-to-skin care practice and minimize the existing regional variations in SSC practice in the country. Additionally, taking measures to increase ANC uptake and strengthening ANC counseling with due consideration of skin-to-skin care component can enhance the SSC practice in the community.

\section{Abbreviations}

ANC: Antenatal care

AOR: Adjusted odds ratio

CI: Confidence interval

COR: Crudes odds ratio
CS: Cesarean section

DHS: Demographic and Health Survey

EAs: Enumeration areas

EDHS: Ethiopian Demographic and Health Survey

KMC: Kangaroo mother care

LBW: Low birth weight

SNNP: Southern Nations, Nationalities, and People's

SSC: Skin-to-skin care

WHO: World Health Organization.

\section{Data Availability}

The data were obtained from The DHS Program repository. The authors have no mandate to share the data set or make it publicly available. However, the data can be accessed upon a reasonable request from the DHS Program website (available at https://www.dhsprogram.com/data/availabledatasets.cfm).

\section{Conflicts of Interest}

The authors declare that they have no conflict of interest.

\section{Acknowledgments}

We thank ICF Macro International for allowing us to use the 2016 Ethiopian Demographic and Health Survey data set for free.

\section{Supplementary Materials}

Supplementary 1. Table S1: explanatory variables categorization and coding.

Supplementary 2. Table S2: STROBE 2007 (v4) Statement-checklist of items that should be included in reports of cross-sectional studies. 
Supplementary 3. Table S3: the distribution of birth assistance by region and residence, EDHS 2016.

\section{References}

[1] S. Chawanpaiboon, J. P. Vogel, A.-B. Moller et al., "Global, regional, and national estimates of levels of preterm birth in 2014: a systematic review and modelling analysis," The Lancet Global Health, vol. 7, no. 1, pp. e37-e46, 2019.

[2] H. Blencowe, J. Krasevec, M. de Onis et al., "National, regional, and worldwide estimates of low birthweight in 2015, with trends from 2000: a systematic analysis," The Lancet Global Health, vol. 7, no. 7, pp. e849-e860, 2019.

[3] United Nations Children's Fund (UNICEF), World Health Organization (WHO). UNICEF-WHO low birthweight estimates: levels and trends 2000-2015, World Health Organization, Geneva, 2019, Contract No.: 2019 Licence: CC BY-NCSA 3.0 IGO.

[4] A. C. C. Lee, H. Blencowe, and J. E. Lawn, "Small babies, big numbers: global estimates of preterm birth," The Lancet Global Health, vol. 7, no. 1, pp. e2-e3, 2019.

[5] World Health Organization Department of Reproductive Health and Research, Kangaroo mother care: a practical guide, World Health Organization, Geneva, Switzerland, 2003.

[6] G. J. Chan, B. Valsangkar, S. Kajeepeta, E. O. Boundy, and S. Wall, "What is kangaroo mother care? Systematic review of the literature," Journal of global health, vol. 6, no. 1, 2016.

[7] WHO, Guideline: protecting, promoting and supporting breastfeeding in facilities providing maternity and newborn services, World Health Organization, Geneva, Switzerland, 2017.

[8] A. Conde-Agudelo, J. M. Belizán, and J. Diaz-Rossello, "Kangaroo mother care to reduce morbidity and mortality in low birthweight infants," Cochrane Database of Systematic Reviews, vol. 3, 2011.

[9] B. Worku and A. Kassie, "Kangaroo mother care: a randomized controlled trial on effectiveness of early kangaroo mother care for the low birthweight Infants in Addis Ababa, Ethiopia," Journal of Tropical Pediatrics, vol. 51, no. 2, pp. 93-97, 2005.

[10] J. E. Lawn, J. Mwansa-Kambafwile, B. L. Horta, F. C. Barros, and S. Cousens, "Kangaroo mother care' to prevent neonatal deaths due to preterm birth complications," International Journal of Epidemiology, vol. 39, Supplement 1, pp. i144i154, 2010.

[11] F. Parvin, M. Rad, and A. Farhat, "Effect of kangaroo care on mother and newborn: a systemtic review," Journal of Gorgan University of Medical Sciences, vol. 20, no. 4, pp. 9-15, 2018.

[12] B. Pouraboli, M. Estabraghi, and Y. Jahani, "The effect of early skin to skin contact on maternal attachment behaviors in neonates after cesarean section," i-Manager's Journal on Nursing, vol. 8, no. 4, p. 10, 2018.

[13] L. Vesel, A.-M. Bergh, K. J. Kerber et al., "Kangaroo mother care: a multi-country analysis of health system bottlenecks and potential solutions," BMC Pregnancy and Childbirth, vol. 15, no. S2, 2015.

[14] S. B. Nguah, P. N. L. Wobil, R. Obeng et al., "Perception and practice of kangaroo mother care after discharge from hospital in Kumasi, Ghana: a longitudinal study," BMC Pregnancy and Childbirth, vol. 11, no. 1, p. 99, 2011.

[15] A. G. Mekonnen, S. S. Yehualashet, and A. D. Bayleyegn, “The effects of kangaroo mother care on the time to breastfeeding initiation among preterm and LBW infants: a meta-analysis of published studies," International Breastfeeding Journal, vol. 14, no. 1, p. 12, 2019.

[16] N. Abdulghani, K. Edvardsson, and L. H. Amir, "Worldwide prevalence of mother-infant skin-to-skin contact after vaginal birth: a systematic review," PLoS One, vol. 13, no. 10, article e0205696, 2018.

[17] The United States Agency for International Development (USAID), Maternal and Child Survival Program, Save The Children, Kangaroo mother care in Ethiopia: Overview, Addis Ababa, Ethiopia, 2018.

[18] Ethiopian Public Health Institute (EPHI)[Ethiopia], ICF, Ethiopia Mini Demographic and Health Survey 2019: Key Indicators, EPHI and ICF, Rockville, Maryland, USA, 2019.

[19] D. A. Berhanu, B.I. Community Based Newborn Care in Ethiopia: Quality of CBNC Programme Assessment Midline Evaluation Report March 2017. Technical Report, UNSPECIFIED. London: IDEAS, London School of Hygiene \& Tropical Medicine: London School of Hygiene \& Tropical Medicine, London, England, 2017.

[20] J. A. Callaghan-Koru, A. Seifu, M. Tholandi et al., "Newborn care practices at home and in health facilities in 4 regions of Ethiopia," BMC Pediatrics, vol. 13, no. 1, p. 198, 2013.

[21] J. A. Callaghan-Koru, A. S. Estifanos, E. D. Sheferaw et al., "Practice of skin-to-skin contact, exclusive breastfeeding and other newborn care interventions in Ethiopia following promotion by facility and community health workers: results from a prospective outcome evaluation," Acta Paediatrica, vol. 105, no. 12, pp. e568-e576, 2016.

[22] F. F. Warnock and T. Castral, "Commentary on:'kangaroo mother care to reduce morbidity and mortality in low-birthweight infants'," Evidence-Based Child Health: A Cochrane Review Journal, vol. 7, no. 2, pp. 877-879, 2012.

[23] Federal Ministry of Health Ethiopia, National strategy for newborn and child survival in Ethiopia: 2015/16-2019/20, D. $\mathrm{MaCH}$, Ed., Federal Ministry of Health Ethiopia, Addis Ababa, Ethiopia, 2015.

[24] Central Statistical Agency (CSA) [Ethiopia] and ICF-International, Ethiopia Demographic and Health Survey 2016, Ethiopia Central Statistical Agency, Addis Ababa, Ethiopia and Rockville, MA, USA, 2016.

[25] T. N. Croft, A. M. Marshall, C. K. Allen, F. Arnold, S. Assaf, and S. Balian, Guide to DHS Statistics, ICF, Rockville, MA, USA, 2018.

[26] D. W. Hosmer and S. Lemeshow, "Applied Logistic Regression,” John Wiley \& Sons, Inc., New York, NY, USA, 2nd edition, 2000.

[27] E. von Elm, D. G. Altman, M. Egger et al., "The Strengthening the Reporting of Observational Studies in Epidemiology (STROBE) Statement: guidelines for reporting observational studies," PLOS Medicine, vol. 4, no. 10, article e296, 2007.

[28] The Last Ten Kilometers Project 2020, Maternal and Newborn Health Care Behaviors and Practices in 115 l10k Districts of Ethiopia: Baseline and Follow-up Surveys 2016-2017, JSI Research \& Training Institute Inc, Addis Ababa, Ethiopia, 2018.

[29] The Last Ten Kilometers Project, Changes in maternal, newborn and child health in 115 rural woredas of Amhara, Oromia, SNNP, and Tigray, 2008-2010: findings from the L10K baseline and midterm surveys, JSI Research \& Training Institute Inc, Addis Ababa, Ethiopia, 2012. 
[30] R. P. Upadhyay, S. K. Rai, and K. Anand, "Community neonatal practices and its association with skilled birth attendance in rural Haryana, India," Acta Paediatrica, vol. 101, no. 12, pp. e535-e539, 2012.

[31] J. Cederfeldt, J. Carlsson, C. Begley, and M. Berg, "Quality of intra-partum care at a university hospital in Nepal: a prospective cross-sectional survey," Sexual \& Reproductive Healthcare, vol. 7, pp. 52-57, 2016.

[32] S. Crowe, A. Prost, M. Hossen et al., "Generating insights from trends in newborn care practices from prospective populationbased studies: examples from India, Bangladesh and Nepal," PLoS One, vol. 10, no. 7, article e0127893, 2015.

[33] I. S. Mustikawati, H. Pratomo, E. Martha, A. I. Murty, and A. C. Adisasmita, "Barriers and facilitators to the implementation of kangaroo mother care in the community - a qualitative study," Journal of Neonatal Nursing, vol. 26, no. 2, pp. 109114, 2020.

[34] G. Seidman, S. Unnikrishnan, E. Kenny et al., "Barriers and enablers of kangaroo mother care practice: a systematic review," PLoS One, vol. 10, no. 5, article e0125643, 2015.

[35] S. Kirchengast, E. Pölzlberger, E. Hafner, I. Stümpflein, and B. Hartmann, "Sex differences in foetal biometry, new-born size and birth outcome," Journal of Life Sciences, vol. 8, no. 1-2, pp. 1-11, 2017.

[36] S. H. Alwasel, Z. Abotalib, J. S. Aljarallah et al., "Sex differences in birth size and intergenerational effects of intrauterine exposure to Ramadan in Saudi Arabia," American Journal of Human Biology, vol. 23, no. 5, pp. 651-654, 2011.

[37] A. Jelenkovic, R. Sund, Y. Yokoyama et al., "Birth size and gestational age in opposite-sex twins as compared to same-sex twins: an individual-based pooled analysis of 21 cohorts," Scientific Reports, vol. 8, no. 1, p. 6300, 2018.

[38] D. Nigatu, D. Haile, B. Gebremichael, and Y. M. Tiruneh, "Predictive accuracy of perceived baby birth size for birth weight: a cross-sectional study from the 2016 Ethiopian Demographic and Health Survey," BMJ Open, vol. 9, no. 12, article e031986, 2019.

[39] A. K. Blanc and T. Wardlaw, "Monitoring low birth weight: an evaluation of international estimates and an update estimation procedures," Bulletin of the World Health Organization, vol. 83, no. 3, pp. 178-185, 2005. 